\title{
Time Evolution Characteristics of Land Use and Industrial Structures: A Case Study of Yichun City, South China
}

\author{
Wei Huang*, Xiaojun Dong, Ru Liu \\ Department of Geographical Science, Yichun University, Yichun, China \\ Email address: \\ weihuang@jxycu.edu.cn (Wei Huang) \\ ${ }^{*}$ Corresponding author
}

\section{To cite this article:}

Wei Huang, Xiaojun Dong, Ru Liu. Time Evolution Characteristics of Land Use and Industrial Structures: A Case Study of Yichun City, South China. Earth Sciences. Vol. 9, No. 5, 2020, pp. 192-200. doi: 10.11648/j.earth.20200905.15

Received: September 2, 2020; Accepted: September 22, 2020; Published: September 29, 2020

\begin{abstract}
With the rapid progress of urbanization in China, its industrial structure presents a diversified development tendency and land resources are becoming scarcer. Focusing on the relationship between land use and industrial structures is conducive to promoting the intensive use of land resources and realizing sustainable socio-economic development. This study selected the city of Yichun as a case of the average level of development of Jiangxi Province, south China. We applied the structural change rate and deviation coefficient indices, combined with mathematical statistical methods, to explore the time dynamic correlation characteristics between land use and industrial structures in this region from 2000 to 2017 . The results show that: (1) The evolution of land structures lags behind the growth of the gross domestic product (GDP); (2) secondary industries are predominant in Yichun's industrial structure, with tertiary industries growing rapidly and the proportion of primary industries declining - and therefore, the level of economic development of this region is in an "intermediate" stage; (3) there is a significant positive correlation between industrial structures and land use structures, and the latter lags behind the former. On this basis, we summarize several problems and propose corresponding measures: (1) Strengthen the macro-control of land; (2) improve the allocation and utilization of land resources; (3) deepen the concept of intensive land use.
\end{abstract}

Keywords: Yichun City, Industrial Structure, Land Use Structure

\section{Introduction}

Currently, China's urbanization process is accelerating, various industrial structures are developing and evolving, and the demand for land is rising with population growth. As a kind of spatial resource in urbanization development, land resources are obviously limited in quantity, and the contradiction between land supply and demand is prominent, which has become a bottleneck in the construction process of many cities [1]. The phenomenon of uncoordinated development in cities and between urban and rural areas is prominent $[2,3]$, and the difference in urbanization among different regions is expanding [4], which is closely related to economic development, presenting the "Matthew Effect" (refers to the phenomenon that the strong get stronger and the weak get weaker) [5]. On the other hand, in the process of rapid urbanization, land use efficiency is low, and a large amount of high-quality cultivated and ecological protection land is occupied, which seriously threatens China's food and ecological security $[6,7]$. Therefore, the intensive use of land resources plays a vital role in improving the level and quality of urbanization, and is also an important way to realize the healthy, orderly, and sustainable development of society - in particular, exploring the rational use of land has become a common concern of society.

The concept of urbanization is not only a question of populations entering cities, but also involves the construction and development of land, industries, and infrastructure. Lu et al. [8] first put forward the concept of "land urbanization," and suggested that an "aggressive" urbanization phenomenon has appeared in recent decades in China. This manifests that the rate of population urbanization is too fast, the urban spatial construction layout appears disorderly or even out of control, and the quality and sustainable development of urbanization are ignored. However, recent studies have shown that in some regions, urbanization lags behind $[9,10]$, and urbanization per 
capita land is too high for coordinated development [11]. In the process of rapid urbanization in China, with industrial economy providing an obvious imprint, land resources in other fields are generally transferred to industrial land, causing negative social and environmental problems to a large extent [12]. Tang et al. [13] pointed out that land urbanization would have a negative impact on the urban ecological effect, while the optimization and upgrading of industrial structures would have a positive effect, indicating that the latter could play a regulating role in the process of urban sustainable development. In fact, the level urbanization of land is the result of the joint influences of population and land scale, economic development, industrial structures, and government policies [14-18]. Population, land, and industrial urbanization are interdependent and form dynamic coupling relationships, and their contact forms and driving mechanisms are also different at different time stages $[19,20]$. Among them, the evolution characteristics of industrial land are regarded as the basic attribute of urban construction land, which is also the manifestation of industrial structure evolution in space $[4,21]$. At present, there are few studies on the relationship between industrial structures and intensive land use [4, 13], and most of them focus on the indicators of construction and evaluation, prediction, and empirical research of land use [22-25], as well as coordinated development in the process of urbanization [2, 11, 26]. Based on the STIRPAT model, Han et al. [27] analyzed the influence of the national industrial structure on land use by using the least square method (FGLS), and pointed out that the improvement of the composition and competition effects of the industrial structure is conducive to promoting intensive land use. From the local and regional perspectives, Zhang et al. [28] evaluated the relationship between industrial structures and urban land use in Anhui Province, east China, and showed three stages of change characteristics in time series with the "threshold effect." The latest research argued

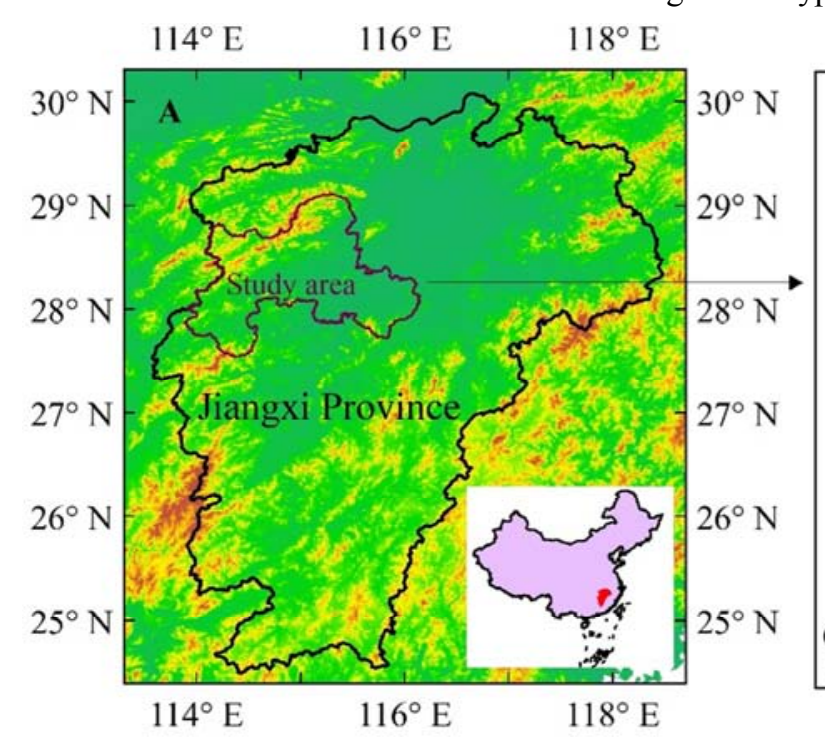

that there exists significant regional disparities in intensive industrial land use and the urban land layout in China [3]. Simple expansion of industrial land cannot guarantee efficient economic output, and urban land use efficiency needs to be improved.

Taken together, previous studies mainly focused on the overall pattern of land use of the whole country or key regional perspectives, but few concerned the relationship between industrial structure and land use in small- and medium-sized underdeveloped cities. Taking the city of Yichun in Jiangxi Province, south China, as an example, this study aimed to empirically analyze the impact of economic development and industrial structure evolution on land use efficiency, and revealed its land use level. Furthermore, some reasonable proposals for land use in Yichun are put forward, which provide scientific reference for coordinating provincial land use and industrial planning.

\section{Study Area}

The city of Yichun, located in the northwest of Jiangxi Province $\left(27^{\circ} 33^{\prime}-29^{\circ} 06^{\prime} \mathrm{N}, 113^{\circ} 54^{\prime}-116^{\circ} 27^{\prime} \mathrm{E}\right)$, south China (Figure 1), is influenced by the subtropical monsoon climate. The city covers an area of $18,680.42 \mathrm{~km}^{2}$, accounting for $6.36 \%$ of the province's total area. It borders, within provincial space, Nanchang in the east, Fuzhou in the southeast, Ji'an and Xinyu in the south, Pingxiang in the southwest, and Jiujiang in the north. It also adjoins Changsha and Yueyang of Hunan Province in the northwest. Its landform types are mainly hills and mountains, with a few plains. In terms of geomorphologic features, the northwest, southwest, and west are surrounded by mountains, belonging to the mountainous landform, which slope to the east and gradually transition to the hilly and plain geomorphic areas. The distribution of various geomorphic types is irregular and roughly in the form of ring structure.

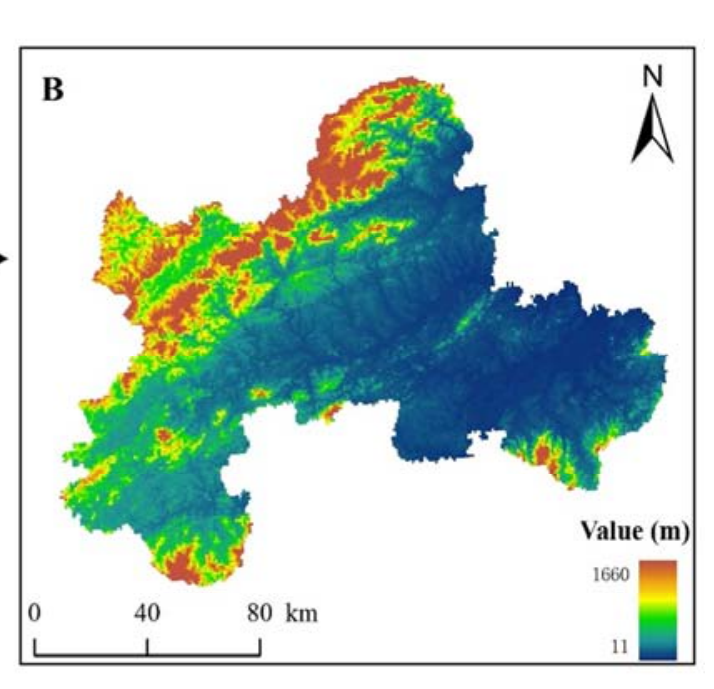

Figure 1. Sketch map with the location of Yichun city. A: The geographical location of Yichun in Jiangxi Province. B: The administrative division of Yichun based on the digital elevation map (DEM), with the color from blue to red representing the elevation from low to high.

By the end of 2017, there were 5.5537 million permanent residents living in this city, including 2.6719 million urban 
residents and 2.8819 million rural residents. The urban population increased by 98,700 over the previous year, while the rural population decreased by 77,400 . The population in rural areas was further transferred to urban areas, with a natural growth rate of $7.63 \%$ and an urbanization rate of $48.11 \%$. In 2017, the gross domestic product (GDP) was 200.332 billion yuan, an increase of $9.0 \%$ over the previous year. The built-up areas of the whole city and the central urban section are $272.52 \mathrm{~km}^{2}$ and $72 \mathrm{~km}^{2}$, respectively.

\section{Data and Methodology}

\subsection{Data Sources}

The basic data of this paper were mainly taken from the "Jiangxi Statistical Yearbook," "The Statistical Bulletin of The National Economic and Social Development of Yichun City (2000-2017)," "China's County Construction Statistical Yearbook," and "China's Urban-Rural Construction Statistical Yearbook."

\subsection{Research Methods}

\subsubsection{Statistical Analysis}

(1) Linear regression analysis. In this paper, SPSS (IBM company: Armonk, USA) and Grapher (Golden company: Golden, USA) softwares were used to analyze the linear regression equation with one variable. The potential causal relationship between the urban construction land use and the structural changes of the secondary and tertiary industries in Yichun was calculated. Then, an $F$ significance test was carried out on the regression results. The regression equation is as follows: $y=\mathrm{a} x+\mathrm{b}$.

(2) Correlation analysis. With SPSS software, we conducted a Pearson correlation analysis of the urban construction land use and the secondary and tertiary industrial structures in Yichun, with the significance test confirmed. The calculation formula is as follows:

$$
r_{x y}=\frac{\sum_{i=1}^{n}\left(x_{i}-\bar{x}\right)\left(y_{i}-\bar{y}\right)}{\sqrt{\sum_{i=1}^{n}\left(x_{i}-\bar{x}\right)^{2}} \sqrt{\sum_{i=1}^{n}\left(y_{i}-\bar{y}\right)^{2}}}
$$

where $r_{x y}$ is the correlation coefficient between variables $x_{i}$ and $y_{i}(i=1,2,3 \ldots, n)$, and $\bar{x}$ and $\bar{y}$ represent the mean values of their respective variables.

\subsubsection{Structural Change Rate and Deviation Coefficient}

The structural change rate is an index to measure the degree of structural change. Its calculation formula is as follows:

$$
D_{i}=\sum_{i=1}^{n}\left|G_{t}-G_{0}\right|
$$

where $D_{i}$ is the rate of structural change, $G_{0}$ is the structure in the base phase (starting year), and $G_{t}$ is the structure in the $t$ phase (ending year) [29].

Based on the formula, the change rates of the industrial and land use structures in Yichun from 2000 to 2017 were obtained, respectively, with $1996 \mathrm{AD}$ as the base year. Specifically, the change rates of the industrial and land use structures were calculated as the sum of the absolute values, derived from the annual change in the proportion of three industrial structures. Finally, the difference between two structural change rates was taken as the deviation coefficient. The greater the deviation coefficient, the lower the coordination between the industrial and land use structures, or else the higher coordination.

\section{Results and Discussion}

\subsection{Current Situation of Land Resource Utilization}

According to the 2017 edition of "the present situation of land use classification" of the China National Standard (GB/T 21010-2017), the land use types in China are divided into cultivated land, garden land, forest land, grassland, commercial and services, industrial and mining warehouses, residential land, public management and public services, special land, transportation, water areas and water facilities, and others. According to the relationship between different industries and land use, land is also divided into primary (including forest land, garden land, grazing land, cultivated land, and other agricultural land), secondary (including industrial land and industrial and mining storage land), and tertiary (including commercial service land, public management and public services land, water conservancy facilities, transportation land, and special land) industrial land.

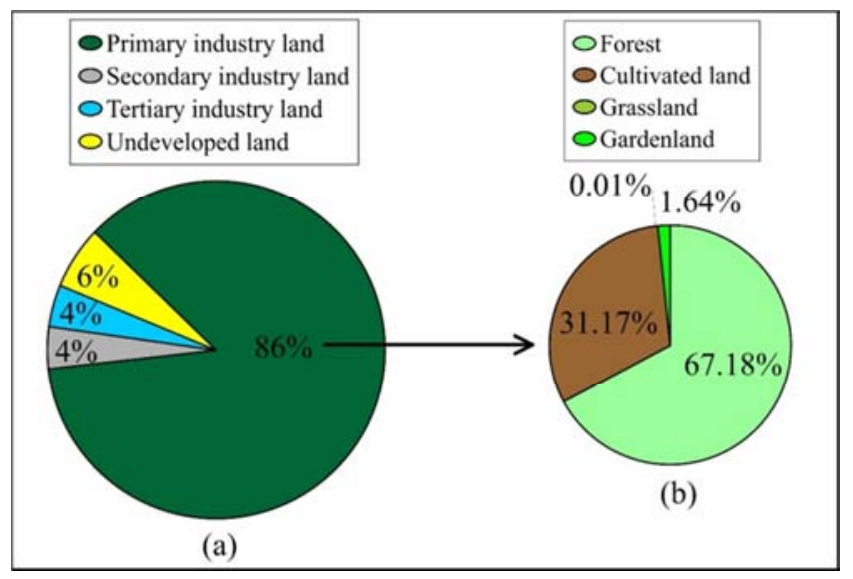

Figure 2. Land use ratio of Yichun in 2017. (a): The proportion of three industries and reserve land. (b): The proportion of the primary industry land use.

As shown in Figure 2, the total land use of the secondary and tertiary industries and undeveloped land only accounts for $14 \%$ of the total land resources of Yichun. The primary industrial land accounts for $86 \%$, far exceeding its proportion in the industrial structure, resulting in an obvious pattern of uncoordinated distribution of land resources. The undeveloped land area accounts for $6 \%$, indicating that the city has sufficient reserve land resources and a large amount of space for urban development, which is a key consideration for future land development. Among the primary industrial land, the proportion of forest land is larger $(67.18 \%)$, which is an 
important aspect in terms of Yichun becoming an ecologically livable city. However, at present, the economic benefit of forest land has not reached its maximum, so there is still great space for the development and utilization of forest land resources in Yichun. On the other hand, according to the existing dual land system in China, rural land has collective ownership, which cannot be directly converted into urban land unless to meet national construction requirements. In this context of incomplete property rights, due to low rent, the use efficiency of collective land leased for industrial production is lower than that of urban land, and the output benefit is thus significantly decreased [30]. Therefore, the way in which to deal with the relationship among rural collective land ownership, contract rights, and use rights, is an important aspect of the healthy and sustainable development of the urbanization of Yichun.

As regards construction land, in 2017, industrial and mining storage land accounted for $25.36 \%$ of the total (Figure 3), which is related to the rich mineral resources in Yichun. In particular, the reserves of lithium mica rank the first in the world, which provides a natural advantage for the industrial development of this region. However, due to the lack of technology in survey and mining, many mines are unduly and extensively exploited, resulting in a series of problems such as land destruction and soil erosion. In the process of excavation, ground subsidence occurs, causing underground water funnels and even triggering earthquakes, resulting in environmental pollution and soil damage [31]. On the other hand, the urban built-up area expanded from $89.69 \mathrm{~km}^{2}$ in 2006 to $184.91 \mathrm{~km}^{2}$ in 2017 . Since 2010 , the process of urban expansion has slowed down to a stable state, but it still shows an annual growth rate of $2 \%-8 \%$ (Figure 4), and the scale of expansion of urban space still presents a relatively fast trend. Taken together, these data indicate that the land use intensiveness of Yichun needs to be improved.

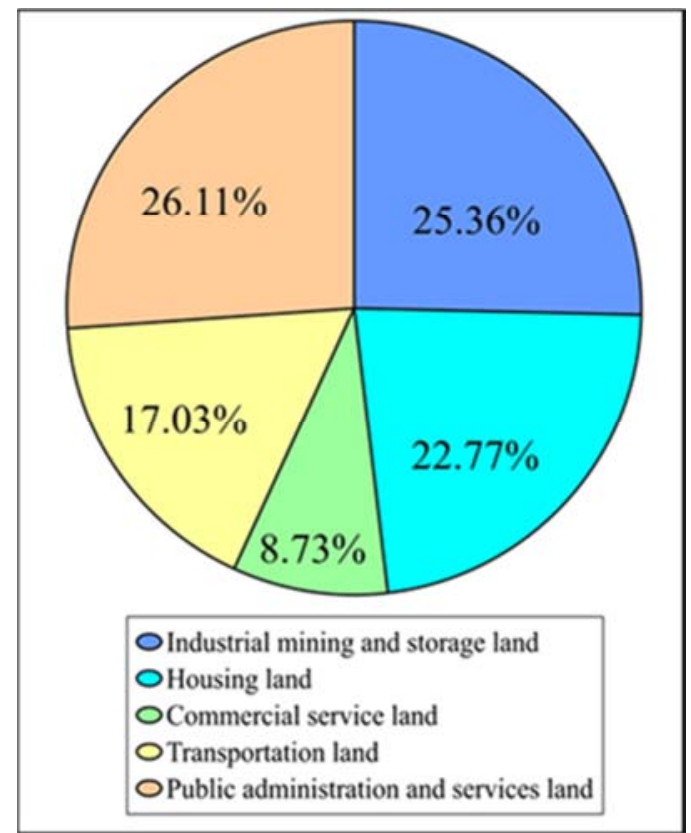

Figure 3. Proportions of various construction land uses of Yichun in 2017.

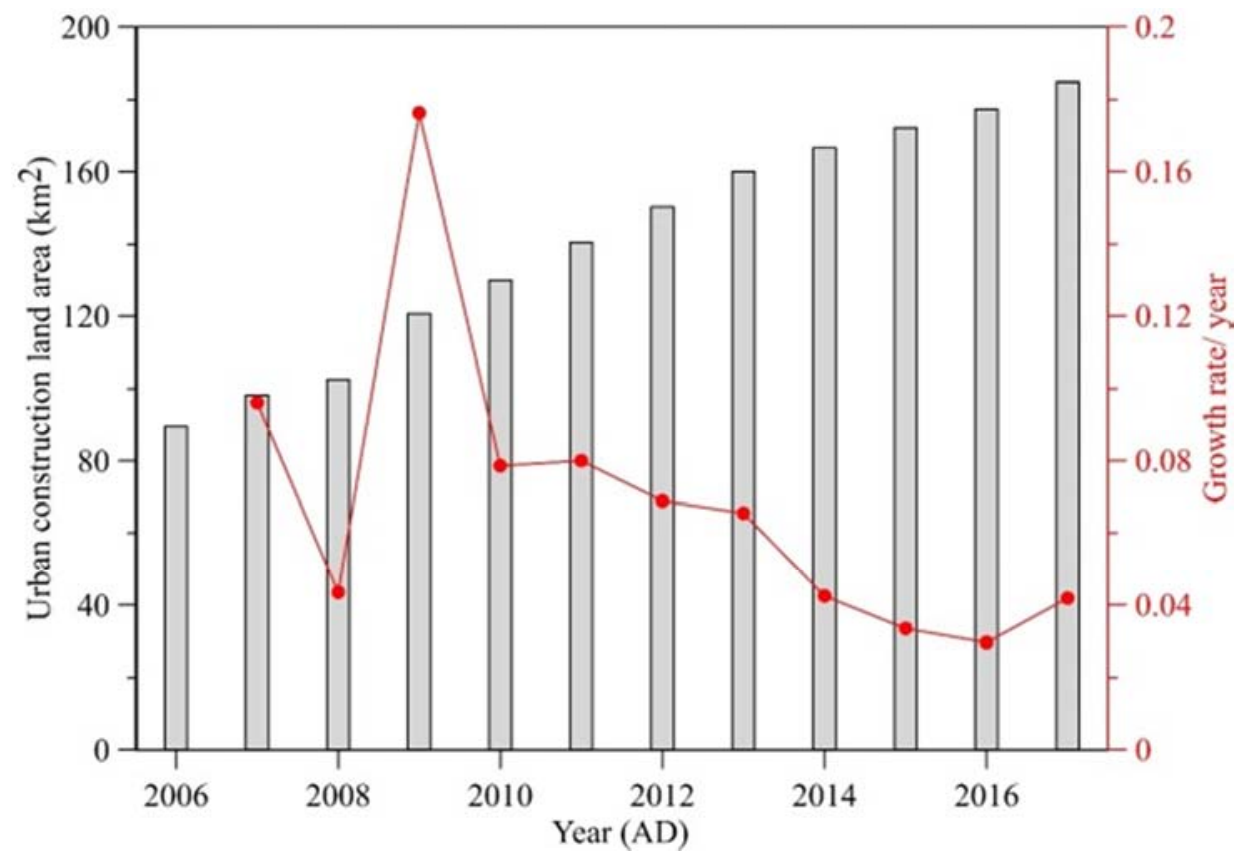

Figure 4. Urban construction land use change in Yichun from 2006 to 2017.

\subsection{Industrial Structure Characteristics}

In terms of economic development, Yichun's GDP continued to grow from 2000 to 2017, with an average annual growth rate of $11.3 \%$ (Figure 5), reflecting the city's strong economic growth momentum. In particular, from 2003 to 2010 , the economy was running at a high and stable level, with an average annual GDP growth rate of over 13\%. After 2010, however, GDP growth slowed gradually, from $12.8 \%$ in 2011 to $9.0 \%$ in 2017 . This is closely related to the macro-control of the state. China is in the throes of economic transformation, 
and slowing down and increasing quality are inevitable. Yichun is in a new stage of industrial transformation, as the city is a traditional agricultural society. Although it has been devoted to developing tourism and the industry in recent years, the industry is still resource-oriented, mainly raw ore production and marketing. The added value of commodities is low, and there is a lack of big industries and projects. A complete industrial chain has not yet been formed, and the development speed is still relatively slow. On the other hand, Yichun is a region with rich tourism resources, not only in terms of beautiful natural tourism resources, but also with rich historical and cultural tourism resources, characterized by "mountains, springs, Zen, agriculture, moon, and ancient history." As early as 2015, Yichun had one 5A scenic spot, four $4 \mathrm{~A}$ scenic spots, and six $3 \mathrm{~A}$ scenic spots. However, these tourism projects and routes are too singular, the connection between scenic spots is not close enough, and all belong to short-distance tourism scenic spots, with the characteristic culture not being strong enough. Therefore, it is an inevitable trend and choice for sustainable development to slow down the growth rate and to improve the development quality of the secondary and tertiary industries.

According to the economic and industrial theories of Kuznets [32] and Chenery et al. [33], the process of industrialization can be divided into five stages, namely, the pre-industrial stage (where the proportion of primary industries is more than $40 \%$ ), the early stage of industrialization $(20 \%-40 \%)$, and the medium $(<20 \%)$, late $(<10 \%)$, and post-industrial $(<5 \%)$ stages. As seen in Figure 6, the proportion of the city's primary industries is shrinking to $12.7 \%$. Meanwhile, the proportion of secondary industries shows an overall upward trend from 2000 to 2011, with a slowing trend after 2011, but its proportion is still far higher than that of primary and tertiary industries. As regards tertiary industries, the overall trend is rising, far exceeding that of primary industries, reaching $41.3 \%$ in 2017 , which is close to that of secondary industries. Since 2002, the three major industrial structures have undergone qualitative changes, with the transformation of Yichun's industrial structure from "primary industry-dominated" to "secondary industry-dominated" and even "tertiary industry-dominated," which is also in line with the industrial layout planning of Jiangxi Province. From this perspective, the industrial development of Yichun has entered the middle stage, that is, its industrial structures have changed from 35.6:33.5:30.9 (the ratio of primary/secondary/tertiary respectively) in 2000 to $14.3: 45.6: 40.1$ in 2017 . However, there is still a certain gap between the industrial structure in 2017 and the industrial optimization goal (10:51:39) set in "The 13th Five-year Plan for National Economic and Social Development of Yichun" [34]. At present, the local government is further strengthening the development of secondary industries, implementing the strategy of "invigorating the industry and strengthening the city," promoting industrial upgrading, and developing a new energy market represented by "lithium electricity." On the other hand, the advantages of local mineral and tourism resources is being given full play to, realizing the parallel development of secondary and tertiary industries. Therefore, the proportion of primary and secondary industries still needs to be further optimized, and the proportion and quality of tertiary industry also needs to be further improved.

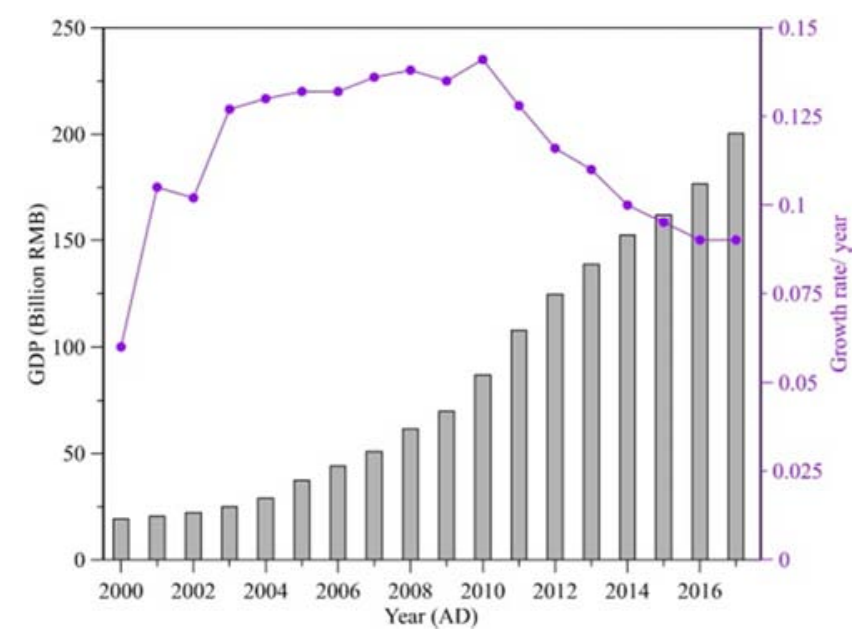

Figure 5. The GDP of Yichun and associated growth rate from 2000 to 2017. Of note is that the GDP values were calculated at current prices, while growth rates were calculated at comparable prices.

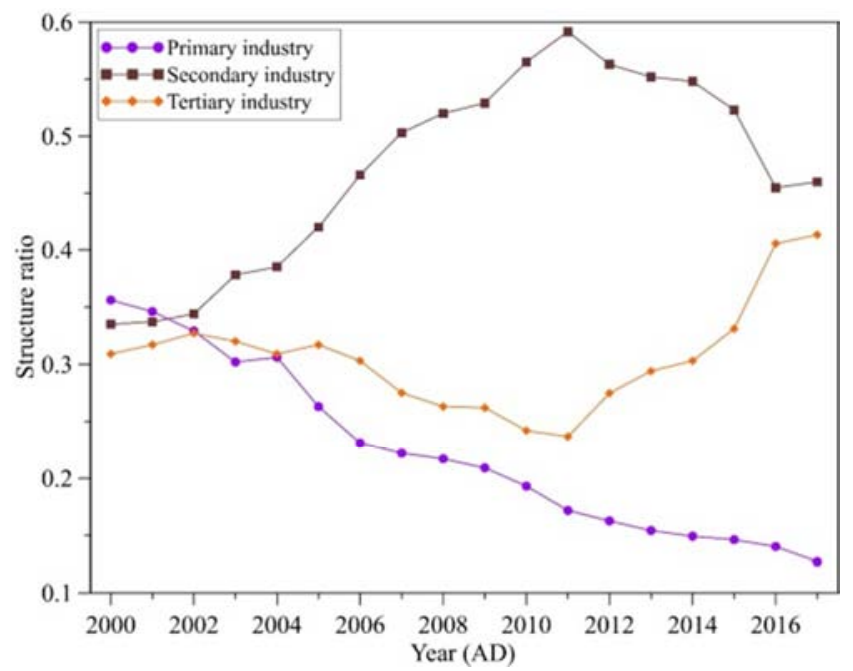

Figure 6. Changes in the proportion of three industrial structures in Yichun from 2000 to 2017.

As Figure 7 shows, the GDPs of the three major industries in Yichun increase every year. The output growth in the primary industry sector is the slowest and most volatile, falling from a high of $9.6 \%$ in 2009 to a low of $3.5 \%$ in 2013. The growth of the secondary industry sector is the largest, with an average annual increment of more than 6 billion yuan; however, its overall growth rate rose first and then fell-from $8.7 \%$ in 2000 to $23.5 \%$ in 2003 and then to $8.7 \%$ in 2017 - with more fluctuation than the other two industries. The growth rate of the output value of the tertiary sector is relatively stable, undulating between $7 \%$ and $13 \%$, with strong continuity. To sum up, the secondary industry sector in Yichun has developed the fastest in recent years. Since 2015, the growth rate of the tertiary industry sector has exceeded that of the secondary industry sector, and the proportion of the former is expected to catch up with the latter. 


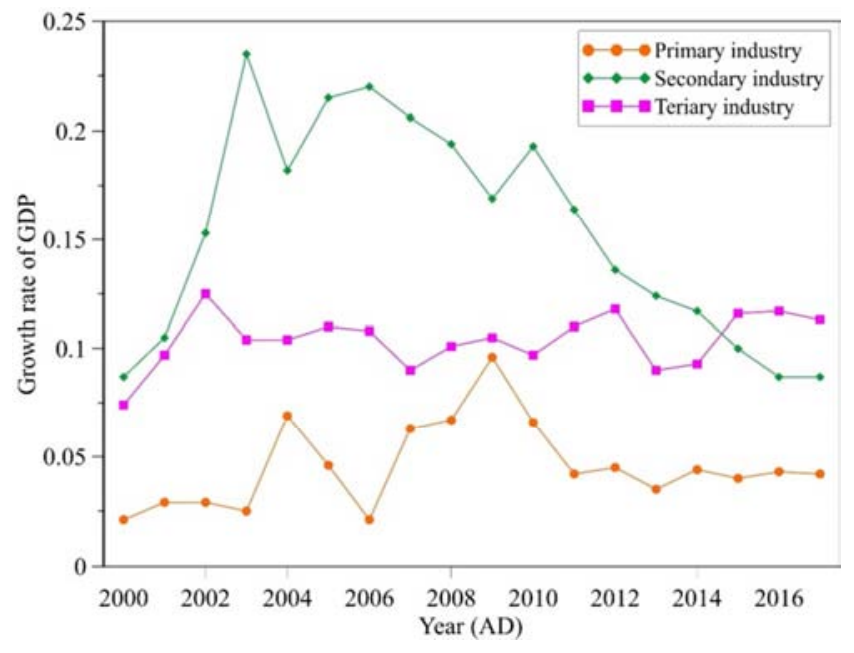

Figure 7. Growth rates of the GDP for three industries in Yichun from 2000 to 2017 , considered at comparable prices.

In 2017, a fixed asset investment of 206.04 billion yuan, with over 5 million yuan per item as the statistical threshold, was supplied, up $13.1 \%$ from the previous year. Investments in the primary, secondary, and tertiary industry sectors reached 7.564 billion yuan, 122.729 billion yuan, and 75.747 billion yuan, up by $20.5 \%, 15.3 \%$, and $9.2 \%$, respectively (Figure 8). As mentioned above, the predominance of investment in the secondary and tertiary industries indicates that the industrial structure and economic development pattern of Yichun have entered a new stage, compared to its traditional agricultural economy and society. The investment in the primary industry sector is extremely small relative to that in the secondary and tertiary industry sectors, and the investment in the secondary industry sector accounts for an overwhelming proportion. Since 2014, the investment in the tertiary industry sector has grown rapidly, but the amount of investment is still far lower than that in the secondary industry sector. However, in 2017, the GDP growth rate of the tertiary industry sector $(11.3 \%)$ surpassed that of the secondary industry sector (8.7\%) (Figure 7$)$. This indicates that the efficiency of intensive land use in the tertiary industry sector has been significantly improved.
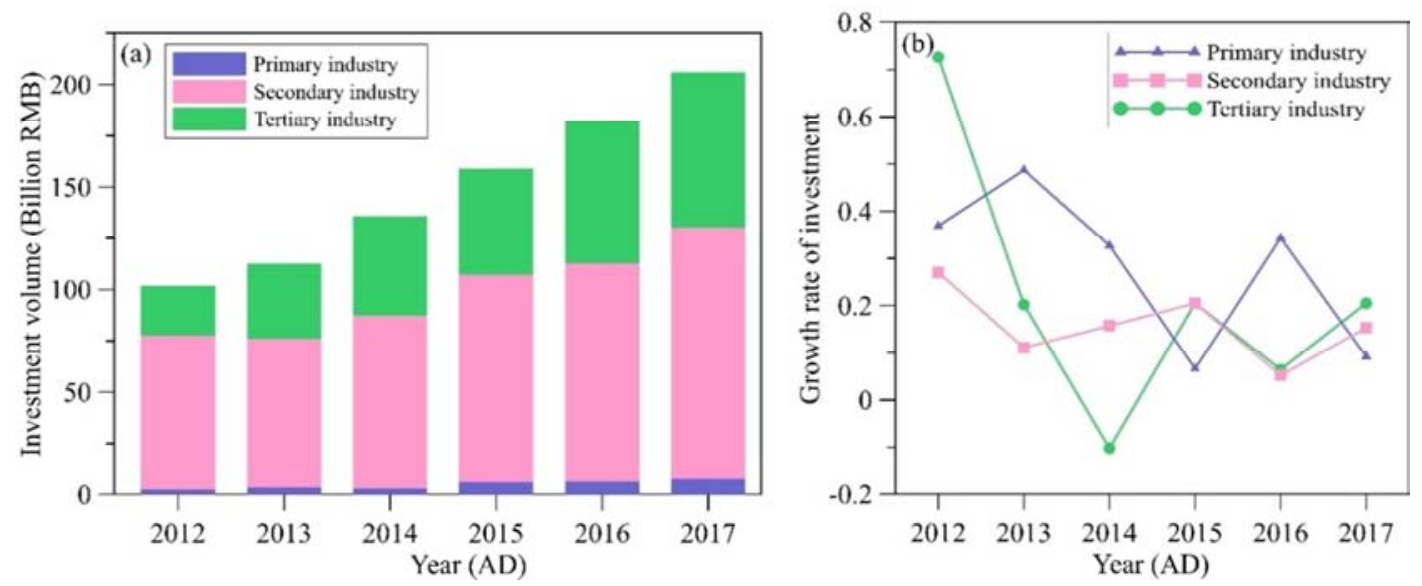

Figure 8. Investment in Yichun from 2012 to 2017. (a): The investment amount of the three industries from 2012 to 2017. (b): The growth rates of investment for three industries from 2012 to 2017.

\subsection{Analysis of the Relationship Between Industrial Structures and Land Use Structures}

From the above discussions, it can be seen that in terms of industrial structure, Yichun is dominated by secondary and tertiary industries. In light of the land use structure, the rate of increase of urban construction land is the most obvious. Hence, the proportion of secondary and tertiary industries in this city was taken as the independent variable $x$, and the proportion of urban construction land was taken as the dependent variable $y$. The results (Figure 9) show that the fitted linear regression equation was $y=-0.07+0.0 .096 x-0.064\left(R^{2}=0.986\right)$ and $\mathrm{F}=695.336>\mathrm{F}_{0.01}=10.04$, indicating a significant correlation at the $\alpha=0.01$ level. The correlation analysis testifies that the secondary and tertiary industries were positively correlated with urban construction land $(r=0.993, n=12, p<0.01)$, suggesting that the evolution of the secondary and tertiary industries is closely related to urban construction land use.

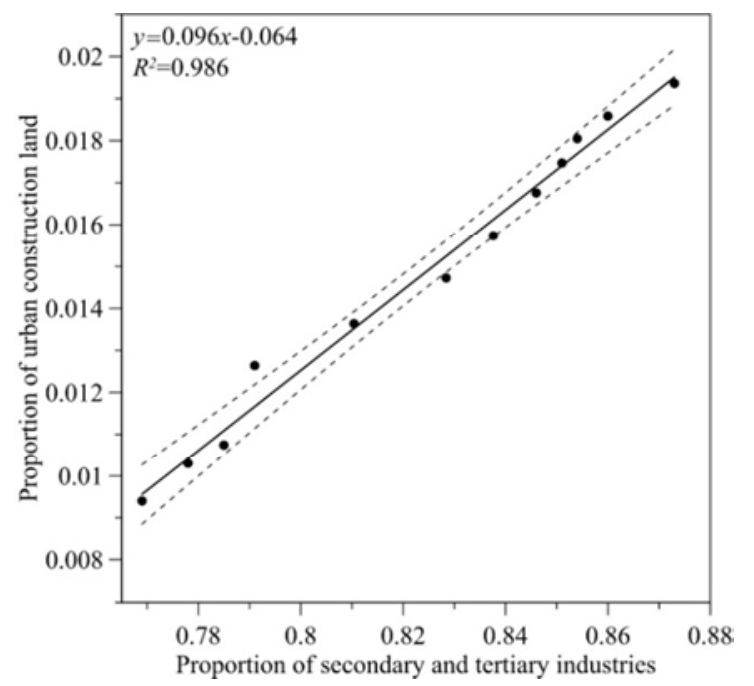

Figure 9. Linear regression result between proportion variations of the secondary and tertiary industries and the urban construction land in Yichun from 2006 to 2017. Dashed lines stand for a 99\% confidence interval. 
The structural change rate is an index used to measure the degree of structural adjustment. As shown in Figure 10, the change rate of the industrial structure in Yichun appears very unstable, with a large range of variations. The cumulative rate of change was up to $95.03 \%$, with an average annual change rate of $4.52 \%$, indicating the unbalanced development of the three industries in Yichun. In contrast, the change rate of the land structure was stable, with total and average annual change rates of $3.23 \%$ and $0.19 \%$, respectively. It can be reasonably inferred that the pace of land structure optimization in Yichun is slow. And therefore, the deviation coefficient between the two was large (Figure 10), with a peak value reaching $91.8 \%$ and showing an increasing trend year by year, thus indicating that change in the industrial structure of Yichun is faster than that of its land use structure, that is, the change of Yichun's land use structure lags behind the development of its industrial structure.

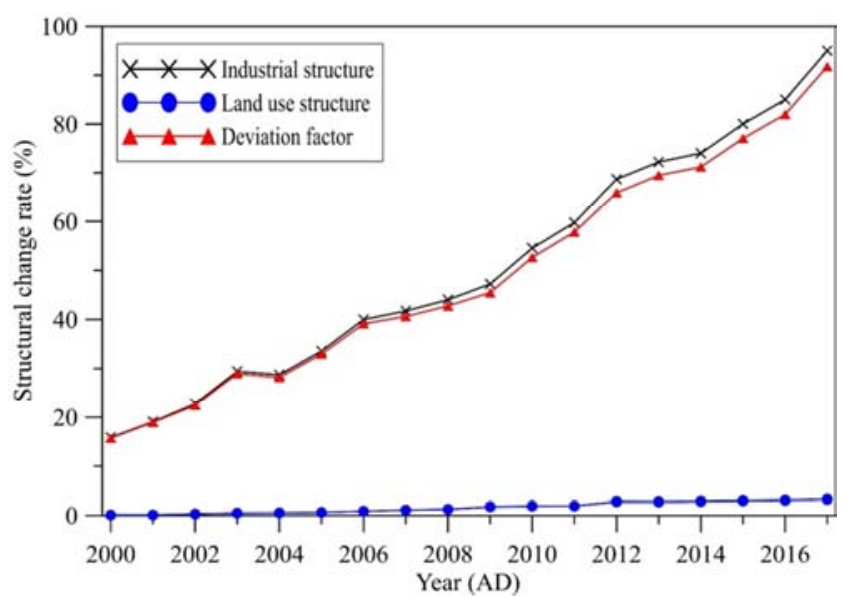

Figure 10. Structural change rates for industries and land use and related deviation coefficients in Yichun from 2000 to 2017.

\subsection{Influence of Industrial Structure Evolution on Intensive Land Utilization}

Intensive use of land means that land utilization and economic benefits are constantly maximized by rational distribution and optimization of land structure, following the principle of sustainable development, and by optimizing labor force, technology, oneself, and land distribution [3]. Land intensification includes three aspects. First, land output is highly efficient, that is, land input and land output optimization. Second, the land layout and structure are rational in the process of the allocation of land resources. Third, the coordinated and unified development of the economy, society, and ecological environment should be realized while pursuing the maximization of economic benefits [35]. The evolution of industrial structures affects the intensive use of land by influencing the structure, efficiency, and intensity of land input.

The level of intensive land use is closely related to the regional economy, stage of urban development, and different industrial characteristics [24]. The proportions of industrial land and industrial structures in Yichun are obviously unbalanced, and the layouts of industrial land and industrial structures are far from coordination. As discussed above, the current industrial development of Yichun falls in the middle stage, characterized by rapid industrial development. However, the layout of land use obviously lags behind that of economic development in Yichun, and the internal structure of land use is not coordinated. The primary industry sector occupies more than $80 \%$ of the land, but its output economic benefit is less than $20 \%$, whose contribution rate to the economy is much lower than that of the other two industry sectors. In contrast, the land use for secondary and tertiary industries occupy a low proportion, but their GDP contribution rate is high. Among the land use of the primary industry sector, the forest land occupies a large area, which is not in accordance with its corresponding economic benefits. The efficiency of land use is thus low, resulting in serious waste of land resources, as well as ecological environmental problems, which have restricted the economic development of Yichun.

\section{Conclusions and Proposals}

\subsection{Conclusions}

In this study, the dynamic change linkages between the land use structure and the industrial structure of Yichun, based on the structural change rate and deviation coefficient indices, were discussed, combined with mathematical statistical methods. The following preliminary conclusions are drawn:

(1) The evolution of the land structure of Yichun lags behind its GDP growth. The proportion of reserve land still to be developed and utilized is $6 \%$, which includes sufficient space for development. However, there exists some problems, such as the waste and destruction of land resources in industrial land, the low economic benefits associated with the land use of the primary industry sector, and the degree of intensive utilization of land still needs to be improved.

(2) At present, the industrial structure of Yichun falls in the "secondary industry-dominated" mode, corresponding to economic development level of the middle stage. However, since 2015, the GDP growth rate of the tertiary industry sector has surpassed that of the secondary industry sector, and it is expected to transition to the "tertiary industry-dominated" mode in the near future.

(3) There is a significant positive correlation between the industrial structure and the land use structure of Yichun. However, they are not coordinated in terms of structural change rate, with the land use structure lagging behind the industrial structure. The primary industry sector accounts for $86 \%$ of the land area, but has a lower GDP contribution of $12.7 \%$; while the secondary and tertiary industrial land uses account for only $8 \%$, producing over $80 \%$ of the GDP. Thus, the land use structure of Yichun needs further optimization and adjustment.

\subsection{Proposals}

(1) Strengthening macro-control over land. The local government should strengthen the supervision of land use from a high to a lower level of administration, should improve 
relevant laws and regulations, and should heavily punish the responsible parties who engage in unreasonable land use and who cause a decline in soil quality. They should also carry on reasonable planning of land use, and should optimize the land structure. In Yichun, there is a large amount of forest land, thus resulting in a high environmental bearing capacity, meaning Yichun can become an ecologically livable city. In the process of land use planning in Yichun, it is necessary to increase the comprehensive utilization of land under the premise of protecting the ecological environment, so as to realize the maximization of interests.

(2) Improving the rational allocation and utilization of land resource structure. According to the development trend of the industrial structure, the land use structure should be rationally optimized, and the coordinated allocation of primary, secondary, and tertiary industries should be paid attention to. The production potential of land resources should be explored by improving the depth and breadth of land resources development and utilization. In the use of forest land, bamboo- and camellia-related products should be developed, and the market and sales channels should be expanded. Under the condition of protecting the ecological environment, wetland and forest parks should be developed to drive the development of tourism and to build an ecologically civilized city. We should strengthen the protection of cultivated land, further tap its potential, and realize intensive agriculture land with water-saving and energy-saving abilities. On the other hand, Yichun is rich in mineral resources, including energy minerals, chemical and metallurgical-used non-metallic minerals, building materials, and other non-metallic minerals. The reserves of lithium mica in Yichun rank the first in the world. Hence, it is necessary to make full use of resource advantages to intensively develop the secondary industry sector, such as new lithium electric energy with a potentially huge market, so as to form a more systematic and perfect industrial chain.

(3) Strengthen the concept of intensive land use and improve the output value of land per unit area. Intensive land use is the adjustment of land use in time, space, layout, and structure. In terms of time, in the process of land development and utilization, the soil quality should be protected and improved with the aim of land sustainable development. From the perspective of space, the intensification of land use should be strengthened, the potential of land should be further explored, and the comprehensive utilization rate of land should be improved. In the process of urbanization, we should improve the city's supporting facilities, increase the investment and development of the cultural service industries, increase the job opportunities in the city, attract excellent talent, and improve the economic efficiency of the land used for urban construction.

\section{Acknowledgements}

We would like to thank the anonymous reviewers for constructive comments. This work was supported by the Science and Technology Research Project of Education Department of Jiangxi Province (no. GJJ180857), and the
Scientific Research Fund of Yichun University (no. 3360117008).

\section{Conflicts of Interest}

The authors declare that they have no competing interests.

\section{References}

[1] Fang, C. and Ma, H. New city district development and intensive land use in the context of new- type urbanization. China Land Sciences, 2013, 27 (7): 4-9. (In Chinese with English abstract).

[2] Tang, D., Li, B., Qiu, Y. and Zhao, L. Research on urban and rural coordination development and its driving force based on the space-time evolvement taking Guangdong Province as an example. Land, 2020, 9 (8), 253.

[3] Yin, G., Lin, Z., Jiang, X., Qiu, M. and Sun, J. How do the industrial land use intensity and dominant industries guide the urban land use? Evidences from 19 industrial land categories in ten cities of China. Sustainable Cities and Society, 2020, 53, 101978 .

[4] Yang, Y., Jiang, G., Zheng, Q., Zhou, D. and Li, Y. Does the land use structure change conform to the evolution law of industrial structure? An empirical study of Anhui Province, China. Land Use Policy, 2019, 81, 657-667.

[5] Chen, M., Huang, Y., Tang, Z., Lu, D., Liu, H. and Ma, L. The provincial pattern of the relationship between urbanization and economic development in China. Journal of Geographical Sciences, 2014, 24 (1), 33-45.

[6] He, P. and Ni, P. Study on the quality of China's urbanization. Statistical Research, 2013, 30 (06), 11-18. (In Chinese with English abstract).

[7] Liu, S., Yu, Q. and Wei, C. Spatial-temporal dynamic analysis of land use and landscape pattern in Guangzhou, China: Exploring the driving forces from an urban sustainability perspective. Sustainability, 2019, 11 (23), 6675.

[8] Lu, D., Yao, S. and Li, G. Comprehensive analysis of the urbanization process based on China's conditions. Economic geography, 2007, 27 (6): 883-887. (In Chinese with English abstract).

[9] Li, Z. A study on the causes of population urbanization laging behind land urbanization. China Population, Resources and Environment, 2013, 23 (11), 94-101. (In Chinese with English abstract).

[10] Huang, W. and Jiang, X. Relationship between land urbanization and population urbanization for Yichun city, Jiangxi. Shanghai Land \& Resources, 2019, 40 (3), 26-31. (In Chinese with English abstract).

[11] Li, S., Ying, Z., Zhang, H., Ge, G. and Liu, Q. Comprehensive assessment of urbanization coordination: A case study of Jiangxi Province, China. Chinese Geographical Science, 2019, 29 (03), 488-502.

[12] Yang, B. D., Lv, J.; Yang, Y. J., Chen, F. and Liu, G. J. Evolution of Industrial Land Location in Xuzhou City since Chinese Reform and Opening-up. Procedia Engineering, 2017, 198, 1137-1148. 
[13] Tang, M., Li, Z., Hu, F. and Wu, B. How does land urbanization promote urban eco-efficiency? The mediating effect of industrial structure advancement. Journal of Cleaner Production, 2020, 272, 122798.

[14] Lu, X., Ke, N., Kuang, B. and Han, J. Spatial-temporal features and influencing factors of difference in land urbanization level of central China. Economic geography, 2019, 39 (04): 192-198. (In Chinese with English abstract).

[15] Henderson, V. The Urbanization Process and Economic Growth: The So-What Question. Journal of Economic Growth, 2003, 8 (1), 47-71.

[16] Yan, S., Peng, J. and Wu, Q. Exploring the non-linear effects of city size on urban industrial land use efficiency: A spatial econometric analysis of cities in eastern China. Land Use Policy, 2020, 99, 104944.

[17] Tu, F., Yu, X. and Ruan, J. Industrial land use efficiency under government intervention: Evidence from Hangzhou, China. Habitat International, 2014, 43, 1-10.

[18] Masini, E., Barbati, A., Bencardino, M., Carlucci, M., Corona, P. and Salvati, L. Paths to Change: Bio-Economic Factors, Geographical Gradients and the Land-Use Structure of Italy. Environmental Management, 2017, 61 (1), 116-131.

[19] Wang, Y., Yuan, Y., Wang, Y., Zhang, X. and Qiao, W. Relationship and mechanism of coupling development between population and land urbanization: A case study of Jiangsu province. Geographical Research. 2017, 36 (1): 149-160. (In Chinese with English abstract).

[20] Zhang, Y. and Xie, H. Interactive relationship among urban expansion, economic development, and population growth since the reform and opening up in China: An analysis based on a vector error correction model. Land, 2019, 8 (10), 153.

[21] Needham, B., Louw, E. and Metzemakers, P. An economic theory for industrial land policy. Land Use Policy, 2013, 33, 227-234.

[22] Liao, J., Han, F., Zhang, W. and Xu, H. The positive analysis of the effect of urbanization on land utilization efficiency in Changsha, Zhuzhou and Xiangtan. China Population, Resources and Environment. 2010, (2): 30-36. (In Chinese with English abstract).

[23] Lu, Z., Zhang, J. and Li, X. Study on the evaluation of urban industrial land intensive use: A case study of Hefei city. Areal Research and Development, 2013, 32 (2), 154-159+165. (In Chinese with English abstract).
[24] Chen, Y. A comprehensive evaluation of industrial land intensive use in Hubei Province based on typical industrial enterprises. Journal of Resources and Ecology, 2015, 6 (3), 186-191.

[25] Xiong, Y., Chen, Y., Peng, F., Li, J. and Yan, X. Simulation of supply and demand of construction land in Chang-Zhu-Tan urban agglomeration based on intensive land use. Journal of Geographical Sciences, 2019, 29 (8), 1346-1362.

[26] Jiao, L., Deng, F. and Liang, X. Sustainable urbanization synergy degree measures-A case study in Henan Province, China. Sustainability, 2018, 10 (1), 9.

[27] Han, F., Wang, Z. and Yang, H. The effect of industrial structure on intensive urban land use. Resource Science, 2013, (2): 388-395. (In Chinese with English abstract).

[28] Zhang, L., Chen, S. and Chen, B. Measurement and analysis of impact of industrial structure evolution on urban land intensive use in Anhui Province in 1996-2011. Scientia Geograhica Sinica, 2014, 34 (9): 1117-1124. (In Chinese with English abstract).

[29] Zhang, Y., Wang, Q. and Wang, W. Study on the relationship between industrial structure and land structure in China. China Land Science, 2007, 21 (2): 4-11. (In Chinese with English abstract).

[30] Choy, L. H. T.; Lai, Y. and Lok, W. Economic performance of industrial development on collective land in the urbanization process in China: Empirical evidence from Shenzhen. Habitat International, 2013, 40, 184-193.

[31] Chen, H. Discussion on the exploitation and utilization of mineral resources in Yichun. Environment and life, 2014, (22): 10-12. (In Chinese).

[32] Kuznets, S. Modern economic growth: Rate, structure, and spread. New Haven: Yale University Press, 1966.

[33] Chenery, H. B., Robinson, S. and Syrquin, M. Industrialization and growth: a comparative study. A World Bank Research Publicatio. London: Oxford University Press, 1987.

[34] Yichun Development and Reform Commission. Outline of the 13th five-year plan for national economic and social development of Yichun city, 2016, http://drc.yichun.gov.cn/news-show-549417.html. (In Chinese)

[35] Lv, X. Reflections on the economical and intensive use of land resources. The 16th academic annual conference of land branch of Fujian Science Association, 2016. (In Chinese). 